\title{
Anatomia da madeira de Mimosa catharinensis Burkart (Leguminosae - Mimosoideae)
}

\author{
João de Deus Medeiros ${ }^{1 *}$ \\ Márcia Rosana Stefani ${ }^{2}$ \\ ${ }^{1}$ Universidade Federal de Santa Catarina, Departamento de Botânica \\ Campus Universitário Reitor João David Ferreira Lima, Trindade \\ CEP 88040-960, Florianópolis - SC, Brasil \\ ${ }^{2}$ Grupo Pau-Campeche, Florianópolis - SC, Brasil \\ * Autor para correspondência \\ j.d.medeiros@ufsc.br
}

Submetido em 20/04/2017

Aceito para publicação em 09/01/2018

\section{Resumo}

Mimosa catharinensis Burkart é um arbusto lianescente, ocorrendo apenas em duas áreas restritas de restinga no leste de Santa Catarina, Brasil. O presente trabalho apresenta a primeira descrição detalhada da anatomia da madeira de M. catharinensis, baseada em dados quantitativos. A descrição é ilustrada com fotomicrografias tomadas nos três planos anatômicos. Raios muito finos, parênquima paratraqueal, fibras libriformes não septadas, dimorfismo de vasos e poros tendendo a um arranjo diagonal foram encontrados. A estrutura anatômica da madeira é comparada com referências da literatura sobre a família Leguminosae e do gênero Mimosa, considerando seus aspectos filogenéticos, taxonômicos e ecológicos.

Palavras-chave: Endemismo; Mata Atlântica; Restinga

\section{Abstract}

Wood anatomy of Mimosa catharinensis Burkart (Leguminosae - Mimosoideae). Mimosa catharinensis Burkart is a schrubby liana, which occurs in only two restricted areas of coastal restinga in eastern Santa Catarina State, Brazil. The present work shows the first accurate description of the wood anatomy of $M$. catharinensis, based on quantitative features. The description is illustrated with photomicrographs taken in the three principal anatomical sections. Very fine rays, paratracheal parenchyma, libriform non-septated fibers, vessel dimorphism and pores tending toward a diagonal pattern were found. The wood anatomy was checked with the literature of the Leguminosae family and genus Mimosa, considering phylogenetic, taxonomic and ecological aspects.

Key words: Atlantic Forest; Endemism; Restinga 


\section{Introdução}

Mimosa é um dos gêneros mais conhecidos das leguminosas, reunindo mais de 400 espécies, de distribuição predominantemente americana, e com escassos representantes nos trópicos do Velho Mundo (BURKART, 1987). Nas Américas, o gênero se distribui do sul dos Estados Unidos até a região central da Argentina, ausente apenas no Chile, Patagônia e nas montanhas Andinas (BURKART, 1952).

O gênero tem seu centro de distribuição na Argentina, mas também está bem representado na flora sul-brasileira. Burkart (1979) referiu 47 espécies para o estado de Santa Catarina, enquanto Rambo (1966) citou 42 para o estado do Rio Grande do Sul, incluindo desde ervas até árvores.

A anatomia da madeira do gênero Mimosa foi pouco investigada, o que decorre do limitado interesse econômico da maioria de suas espécies. Estudando espécies argentinas, Cozzo (1951) destaca a ampla variação anatômica observada no grupo.

Das espécies sul-brasileiras, foram publicados estudos sobre a anatomia da madeira para Mimosa bimucronata (DC.) O. Ktze. (MARCHIORI, 1980; 1993), Mimosa cruenta Benth. (MARCHIORI, 1985), Mimosa daleoides (MARCHIORI, 1982), Mimosa eriocarpa Benth. (CARNIELETTO; MARCHIORI, 1993), Mimosa scabrella Benth. (RICHTER; CHARVET, 1973; MARCHIORI, 1980; 1995), Mimosa sparsa Benth. (MACCARI; MARCHIORI, 1994), Mimosa trachycarpa Benth. (MARCHIORI; BOLZON DE MUÑIZ, 1997a), Mimosa pilulifera Benth. (MARCHIORI; BOLZON DE MUÑIZ, 1997b), Mimosa tenuiflora (Willd) Poir (OLIVEIRA et al., 2006).

Mimosa catharinensis Burkart é um arbusto lianescente, esparsamente aculeado, com folhas amplas com três a cinco pares de pinas distanciadas e capítulos globosos ou ovalados, pedunculados em racemos apicais paniculados, com flores brancas, glabras, tetrâmeras e com oito estames (BURKART, 1979). O fruto é do tipo craspédio indeiscente, linear-oblongo com acúleos recurvados nas margens (MEDEIROS, 2014). Por apresentar flores com corola tetrâmera e oito estames, Burkart (1979) incluiu a espécie na secção Habbasia, e pela presença de capítulos em racemos paniculados e o hábito arborescente na série Rubicaules. A espécie é heliófila e seletiva higrófila, encontrada na orla de vegetação arbustiva de restinga (BURKART, 1979) e em vegetação de encosta da floresta ombrófila densa (MEDEIROS, 2014).

A espécie tem distribuição restrita ao estado de Santa Catarina e, até recentemente, era conhecida somente uma pequena população localizada no Parque Estadual do Rio Vermelho, Ilha de Santa Catarina. Além de apresentar um endemismo bastante restrito, a espécie é reconhecida como ameaçada de extinção pelo governo brasileiro (MMA, 2008) e incluída na Lista Vermelha da União Internacional para a Conservação da Natureza e dos Recursos Naturais (IUCN, 2013).

A estrutura da madeira de $M$. catharinensis é desconhecida. O presente estudo visa a descrição de sua madeira, bem como a comparação da estrutura observada com a de espécies afins.

\section{Material e Métodos}

O material estudado consiste de amostras de madeira e suas respectivas exsicatas botânicas, que se encontram depositadas no Herbário do Departamento de Botânica da Universidade Federal de Santa Catarina (FLOR), com os seguintes registros:

Brasil. Santa Catarina. Florianópolis: Moçambique, Parque Estadual do Rio Vermelho, 05 novembro 2012, Medeiros 30482, (FLOR); Brasil, Florianópolis: Moçambique, Parque Estadual do Rio Vermelho, 09 agosto 2012, Medeiros 18623, (FLOR); Moçambique, Parque Estadual do Rio Vermelho, 17 agosto 2012, Medeiros 33249, (FLOR).

Para o estudo anatômico da madeira foram preparadas lâminas de cortes e de macerado, obtidos a partir do material coletado de três indivíduos da população localizada no Parque Estadual do Rio Vermelho. As primeiras foram obtidas em micrótomo de deslizamento, com espessura nominal de $18 \mu \mathrm{m}$. Os cortes foram previamente tratados com hipoclorito de sódio (20\%), corados com Azul de Astra e Safranina (BUKATSCH, 1972), e desidratados em série etílica 
e acetato de n-butila para montagem de lâminas permanentes. Lamínulas foram fixadas com o uso de resina Permount.

No preparo de lâminas de macerado usou-se solução de Jeffrey (FREUND, 1970) e o mesmo meio de montagem anteriormente citado.

A descrição da estrutura anatômica microscópica do lenho foi conduzida de acordo com as normas da Copant (1974) e da IAWA Committe (1989), e a cor da madeira determinada com a utilização da Tabela de Munsell (MUNSELL COLOR, 1975).

As análises microscópicas foram feitas em microscópio Carl Zeiss-Jena Laboval 4, e as fotomicrografias obtidas em aparelho Leica MPS30, equipado com fotoautomático.

Para determinação da densidade da madeira foram confeccionados blocos de $1 \mathrm{~cm}^{2}$, a partir dos quais foram colhidos dados para aplicação da equação Db:Ms/Vs, onde: Ms: massa do corpo de prova seco (g); e Vs: volume do corpo de prova em estado saturado $\left(\mathrm{cm}^{3}\right)$.

\section{Resultados}

\section{Descrição da madeira}

\section{Caracteres gerais}

Madeira de alburno e cerne indistintos, pouco brilhante, sem odor e gosto característicos, macia ao corte, de coloração basicamente amarela ou em tonalidades de amarelo (amarelo-palha - MUNSELL HUE 2.5Y 8/4), de textura média e grã direita (Figura 1). A densidade média obtida foi de $0,5971 \mathrm{~g} / \mathrm{cm}^{3}$ (Tabela 1 ).

\section{Caracteres macroscópicos}

\section{Poros}

Poros com distribuição difusa (Figura 2), ligeiramente concentrados no início do anel de crescimento, visíveis a olho nu, bem visíveis sob lente de 10x, sem conteúdos; predominantemente solitários; com leve tendência ao alinhamento diagonal. Placa de perfuração simples. Linhas vasculares bem marcadas, retas, sem conteúdos.
FIGURA 1: Aspecto geral da madeira em seção longitudinal.

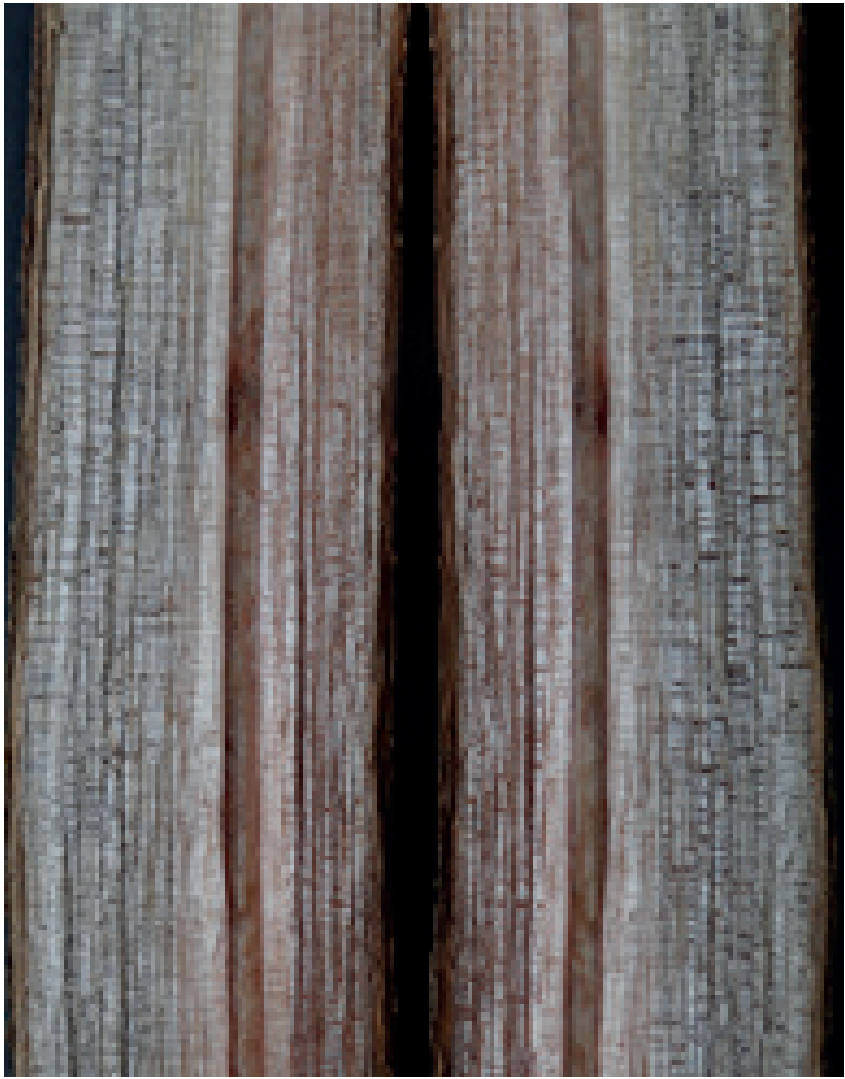

\section{Parênquima axial}

Escasso; imperceptível a olho nu. Sob lente observase o padrão tipicamente paratraqueal, frequentemente vasicêntrico.

FIGURA 2: Corte transversal mostrando porosidade difusa (40x).

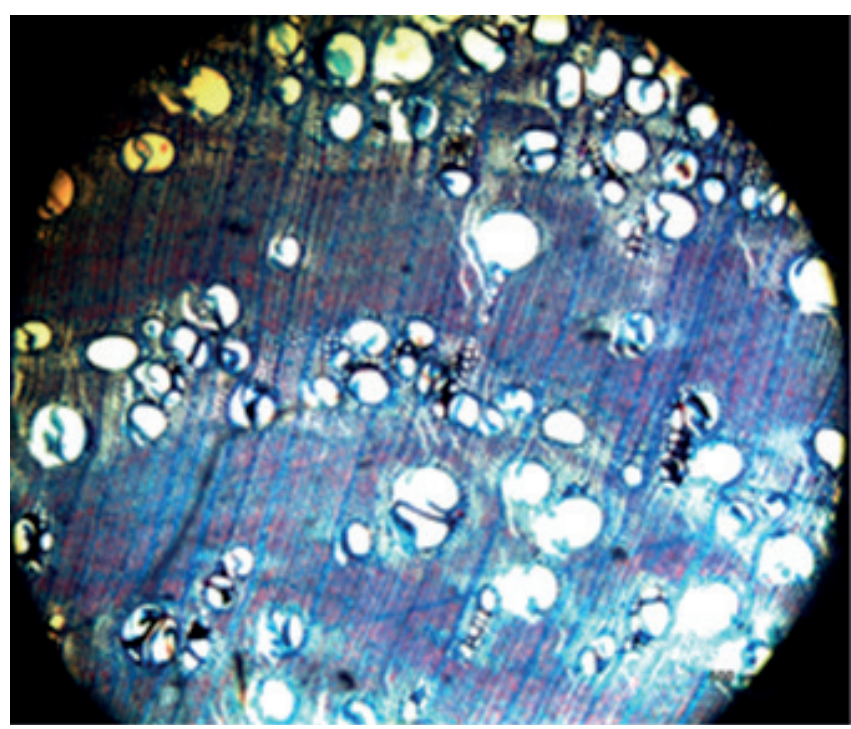


TABELA 1: Dados de pesagem dos blocos para obtenção da densidade da madeira de Mimosa catharinensis.

\begin{tabular}{lccccc}
\hline \multicolumn{1}{c}{ Data } & Bloco 1 & Bloco 2 & Bloco 3 & Bloco 4 & Bloco 5 \\
\hline $\mathbf{1 9 0 2 1 5}$ & 0,8018 & 0,7644 & 0,7616 & 0,7993 & 0,6838 \\
$\mathbf{2 0 0 2 1 5}$ & 0,6995 & 0,6605 & 0,6600 & 0,6918 & 0,5953 \\
$\mathbf{2 3 0 2 1 5}$ & 0,7042 & 0,6652 & 0,6618 & 0,6959 & 0,5975 \\
$\mathbf{2 4 0 2 1 5}$ & 0,7010 & 0,6640 & 0,6620 & 0,6940 & 0,5989 \\
$\mathbf{2 5 0 2 1 5}$ & 0,6767 & 0,6431 & 0,6395 & 0,6705 & 0,5785 \\
$\mathbf{2 6 0 2 1 5}$ & 0,6887 & 0,6509 & 0,6477 & 0,6822 & 0,5868 \\
$\mathbf{2 7 0 2 1 5}$ & 0,6976 & 0,6622 & 0,6583 & 0,6915 & 0,5949 \\
Vol. saturado mL & 1,1 & 1,1 & 1,1 & 1,1 & 1,0 \\
Densidade g/cm & 0,6151 & 0,5846 & 0,5813 & 0,6095 & 0,5949 \\
\hline
\end{tabular}

\section{Parênquima radial}

Raios imperceptíveis a olho nu em secção transversal, finos, de pouco numerosos a numerosos. Em plano tangencial, invisíveis a olho nu, visíveis sob lente de 10x, baixos, não estratificados. Espelhado pouco contrastado.

\section{Anéis de crescimento}

Indistintos a olho nu; marcados fracamente sob lente de 10x por uma ligeira concentração de poros em estreita faixa contínua, no início do anel de crescimento, caracterizando condição intermediária (Figura 2).

\section{Caracteres microscópicos}

\section{Vasos}

Madeira com porosidade difusa, contudo mostrando ligeira concentração de poros no início do anel de crescimento. Vasos com diâmetro tangencial variável, com duas classes de diâmetro (Figura 3); diâmetro tangencial dos vasos de maior calibre 82,3 - 149,8 $210,5 \mu \mathrm{m}$; diâmetro tangencial dos menores 15,8 - 24,4 - 42,1 $\mu \mathrm{m}$; vasos distribuídos em arranjo levemente diagonal. Placa de perfuração exclusivamente do tipo simples (Figura 4), transversal ou levemente oblíqua. Poros de secção oval ou circular, de muito a pouco frequentes a muito numerosos $(8-17,92-35$ poros $/ \mathrm{mm}^{2}$ ), de extremamente pequenos a médios, comprimento dos vasos de menor diâmetro 161,3 278,96 - 438,7 (57,98); vasos maiores, 106,7 - 229,74 - 377,8 $(65,19)$; paredes medianamente espessas
(4 - $6 \mu \mathrm{m})$; presença de vasos solitários e geminados, apresentando em menor proporção múltiplos radiais e racemiformes, que tendem a se concentrar no lenho tardio. Pontuações intervasculares alternas, de pequenas a médias $(3,3-5,6-8,9 \mu \mathrm{m})$, de forma oval ou poligonal (Figura 4). Abertura externa inclusa, estreita, em forma de fenda horizontal. Abertura interna estreita, horizontal. Pontuações raio-vascular e parênquimo-vascular alternas. Pontuações raio-vasculares e parênquimovasculares semelhantes às intervasculares, de pequenas a médias, e com formato circular.

FIGURA 3: Elementos de vaso em seção transversal do lenho (100x).

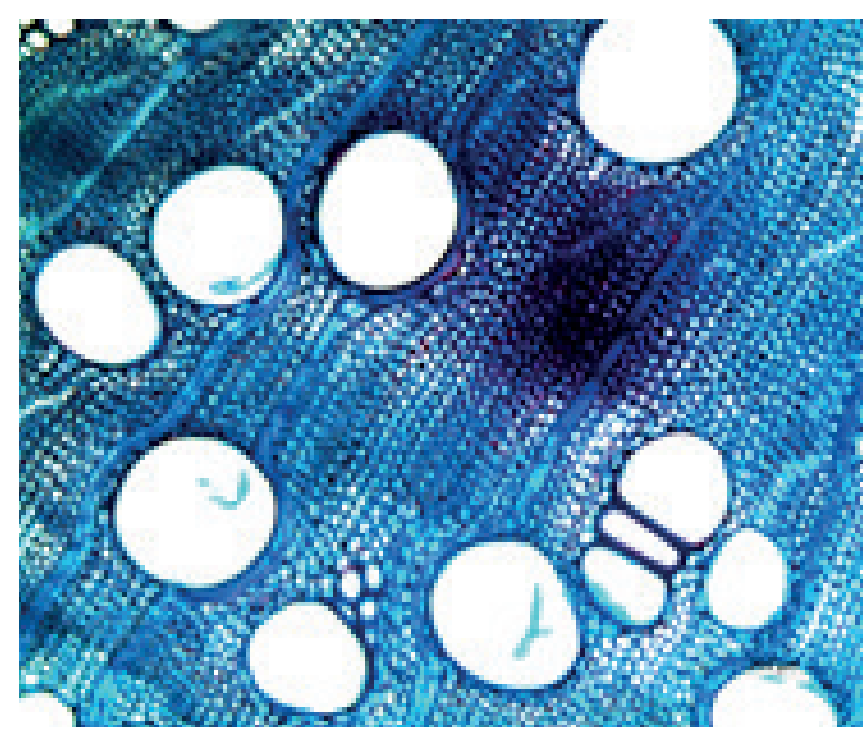

Parênquima axial pouco abundante, não estratificado; em arranjo paratraqueal escasso a vasicêntrico; em secção transversal muitas vezes é difícil a distinção entre células parenquimáticas e fibras de 
paredes finas, especialmente na periferia do parênquima paratraqueal. Células de parênquima axial de 38,9-76,8 - 160,54 $\mu \mathrm{m}$ de comprimento e 4,1 - 11,2 - 16,4 $\mu \mathrm{m}$ de diâmetro tangencial.

FIGURA 4: Placa de perfuração (seta) em seção longitudinal tangencial (400x).

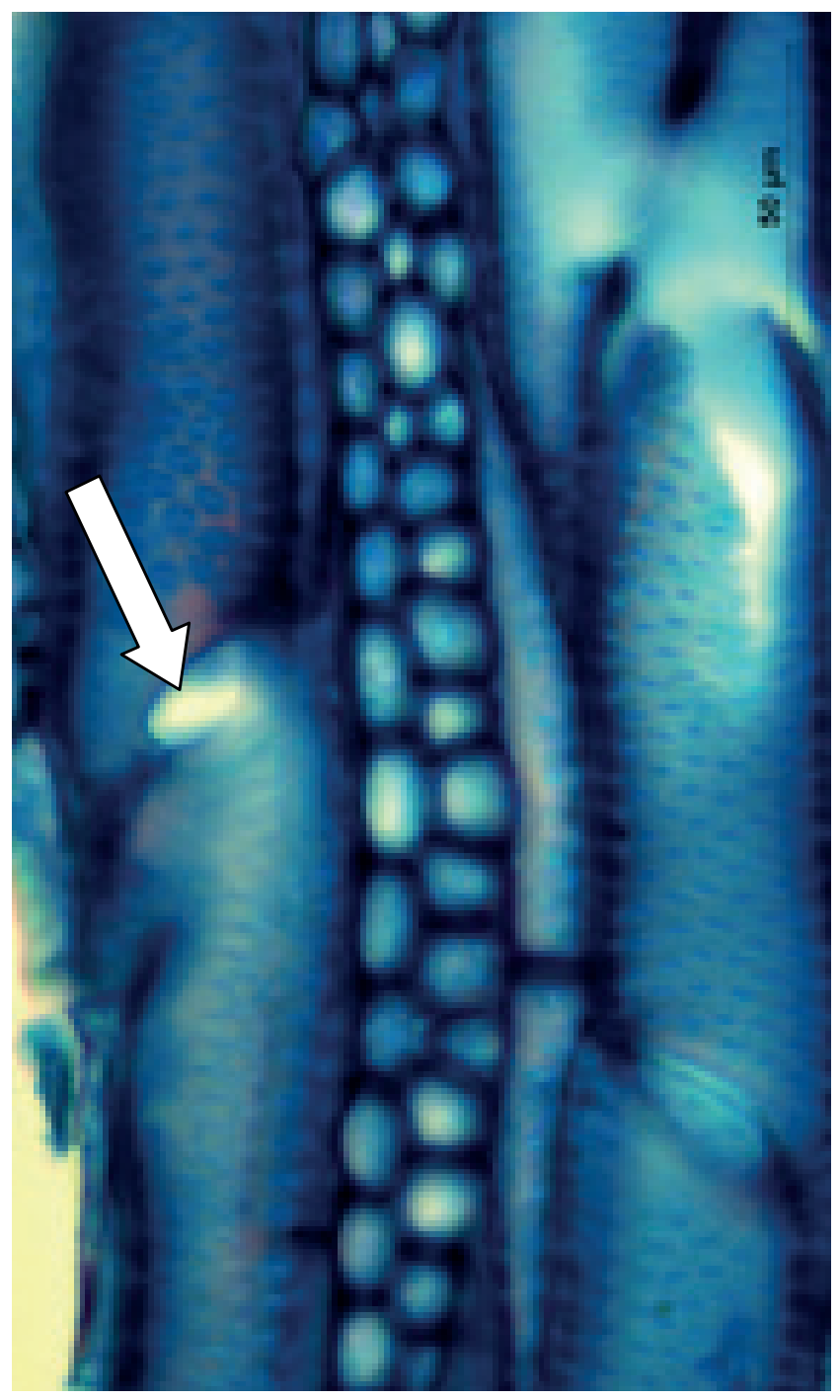

Raios unisseriados escassos e multisseriados mais frequentes, em geral bisseriados ou trisseriados; tetrasseriados raros (Figura 5). Extremamente baixos a muito baixos com 2 - 9,86 - 26 células $(76,5$ - 168,9 - 335,3 $\mu \mathrm{m})$, de extremamente finos a estreitos com $1-2,28-4$ células $(5,9-23,5-35,3 \mu \mathrm{m}$ de largura). Parênquima radial representado por raios sempre homogêneos (Figura 6), com frequência de 4-6,44-9 raios $/ \mathrm{mm}$, desprovidos de tipos especiais de células. As células das extremidades são usualmente mais altas e curtas, embora procumbentes.

FIGURA 5: Raios em seção longitudinal tangencial (100x).

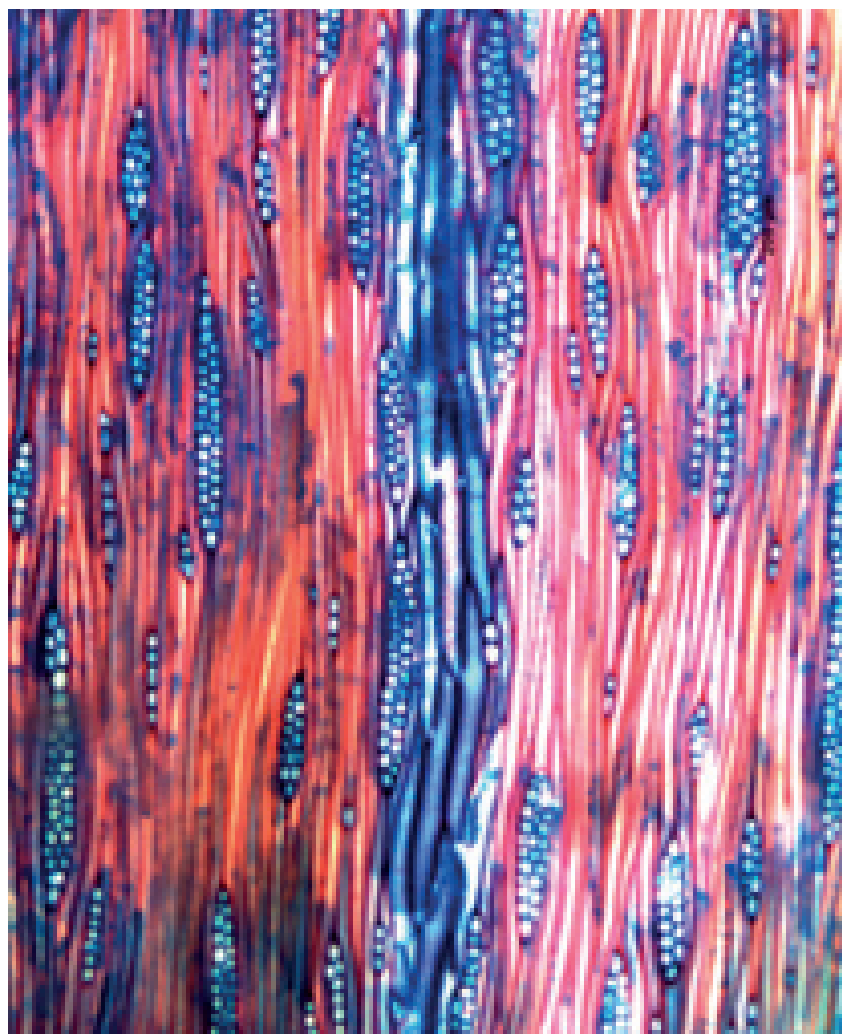

FIGURA 6: Raio homogêneo em seção longitudinal radial (200x).

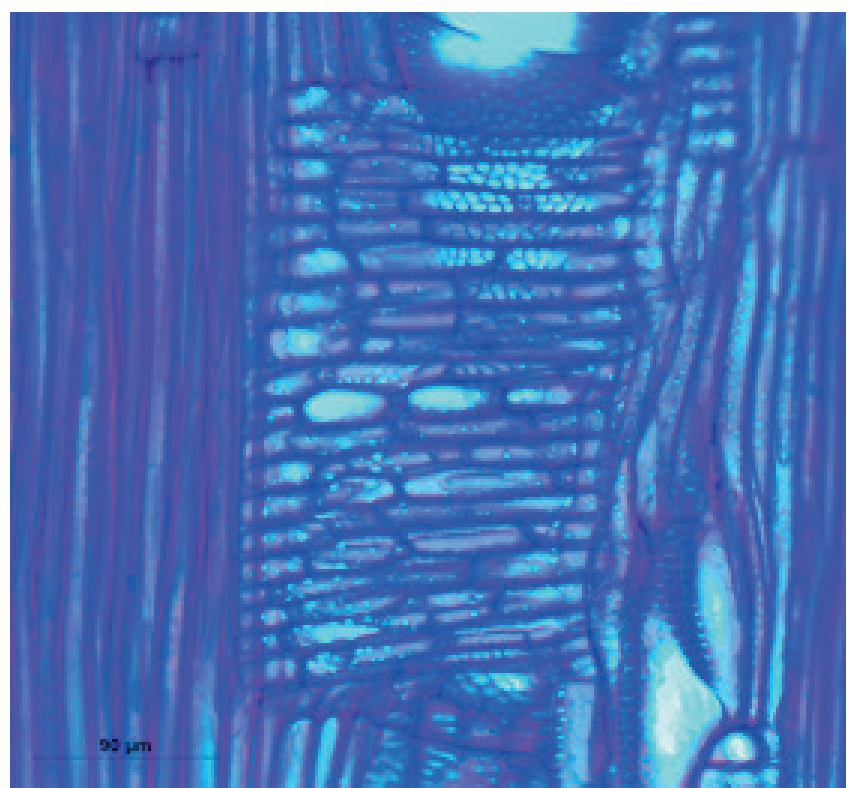


Fibras libriformes, não septadas, com paredes delgadas a espessas, com pontuações simples, diminutas; de extremamente curtas a curtas $(206,45$ - 311,22 $438,71 \mu \mathrm{m})$, de estreitas a médias $(10-16-28 \mu \mathrm{m})$, e com paredes muito delgadas $(1,1-2,62-3,4 \mu \mathrm{m})$. Os dados quantitativos referentes às características anatômicas são apresentados na Tabela 2 .

\section{Discussão}

Diversas características anatômicas observadas no lenho de $M$. catharinensis correspondem às características atribuídas à família Leguminosae, entre as quais são destacadas: vasos solitários a múltiplos, placas de perfuração simples, pontoações intervasculares guarnecidas e alternas; fibras com pontoações simples a diminutas areoladas; raios homocelulares compostos por células procumbentes e parênquima axial paratraqueal (BARETTA-KUIPERS, 1981; WHEELER; BAAS, 1992).

Mimosa catharinensis apresenta algumas características anatômicas do lenho atribuídas às lianas (CARLQUIST, 1991; BAMBER; TER WELLE, 1994), como a presença de vasos com diâmetros distintos (dimorfismo de vasos). Essa característica confere grande eficiência na condução, através dos vasos largos, e grande segurança, através dos vasos estreitos (CARLQUIST, 2001; EWERS et al., 1991).

Carlquist (1985) menciona que o comprimento dos elementos de vaso está mais relacionado com gêneros e espécies próximas do que com o hábito, contudo podem ser verificadas diferenças quando comparadas lianas e árvores da mesma espécie. As Leguminosas apresentam elementos de vaso muito curtos a médios, não ultrapassando $800 \mu \mathrm{m}$ (BARETTA-KUIPERS, 1981; WHEELER; BAAS, 1992), o que foi corroborado no estudo com $M$. catharinensis, já que o comprimento médio dos vasos não chega a $300 \mu \mathrm{m}$, com valor máximo registrado de 438,7 $\mu \mathrm{m}$.

Porosidade difusa, elementos de vasos predominantemente solitários, curtos e desprovido de apêndices, com placas de perfuração simples e pontoações intervasculares alternas, são características observadas em $M$. catharinensis e compartilhadas pela grande maioria das espécies de Mimosa estudadas. Cozzo (1951) chega a afirmar que a presença de poros geralmente solitários ou em curtos múltiplos, com distribuição difusa, e de parênquima axial escasso são características comuns no gênero Mimosa.

TABELA 2: Dados quantitativos da madeira. Para cada característica são apresentados mínima, média, máxima e desvio padrão.

\begin{tabular}{|c|c|c|c|c|}
\hline Característica & Mín & Méd & Máx & Desvio Padrão \\
\hline$\varnothing$ tangencial dos vasos $(\mu \mathrm{m})$ & 82,3 & $\underline{149,8}$ & 210,5 & 37,33 \\
\hline$\varnothing$ tangencial vasos menores $(\mu \mathrm{m})$ & 15,8 & $\underline{24,44}$ & 42,1 & 6,63 \\
\hline Frequência de vasos $\left(\mathrm{mm}^{2}\right)$ & 8 & $\underline{17,92}$ & 35 & 5,8 \\
\hline Comprimento vasos menores $(\mu \mathrm{m})$ & 161,3 & $\underline{278,96}$ & 438,7 & 57,98 \\
\hline Comprimento vasos maiores $(\mu \mathrm{m})$ & 106,7 & $\underline{229,74}$ & 377,8 & 65,19 \\
\hline Agrupamento de vasos & 1 & $\overline{3,76}$ & 13 & 4,06 \\
\hline$\varnothing$ da pontoação intervascular $(\mu \mathrm{m})$ & 3,3 & $\underline{5,62}$ & 8,9 & 1,04 \\
\hline Comprimento das fibras $(\mu \mathrm{m})$ & 206,45 & $\underline{311,22}$ & 438,71 & 63,64 \\
\hline Espessura da parede das fibras $(\mu \mathrm{m})$ & 1,1 & $\underline{2,62}$ & 3,4 & 0,64 \\
\hline$\varnothing$ do lúmen das fibras $(\mu \mathrm{m})$ & 6,7 & $\underline{9,46}$ & 13,3 & 1,83 \\
\hline Largura dos raios ( $\mathrm{n}^{\circ}$ células) & 1 & $\underline{2,28}$ & 4 & 0,72 \\
\hline Largura dos raios $(\mu \mathrm{m})$ & 5,9 & $\overline{23,52}$ & 35,3 & 8,31 \\
\hline Altura dos raios ( $\mathrm{n}^{\circ}$ células) & 2 & $\underline{9,86}$ & 26 & 6,27 \\
\hline Altura dos raios $(\mu \mathrm{m})$ & 76,5 & $\underline{168,95}$ & 335,3 & 67,02 \\
\hline Frequência de raios (mm linear) & 4 & $\overline{6,44}$ & 9 & 1,27 \\
\hline Comprimento parênquima axial $(\mu \mathrm{m})$ & 38,9 & $\underline{76,80}$ & 160,54 & 31,78 \\
\hline$\varnothing$ tangencial parênquima axial $(\mu \mathrm{m})$ & 4,1 & 11,2 & 16,4 & 3,01 \\
\hline
\end{tabular}


A presença de vasos solitários e múltiplos com distribuição difusa, como registrado para $M$. catharinensis, corrobora os dados de Alves e AngyalossyAlfonso (2000), que afirmam ser essas características comuns na flora brasileira, diferentemente do que ocorre em regiões de clima temperado, nas quais outras distribuições como dendríticas e porosas são mais comuns.

Como nas demais espécies de Mimosa estudadas, M. catharinensis apresenta parênquima paratraqueal. Ao parênquima axial paratraqueal nas lianas é atribuída a função de auxílio na recuperação do tecido vascular após injúria (FISHER; EWERS, 1989), de aumento da flexibilidade (PUTZ; HOLBROOK, 1991) ou ainda a função de segurança e manutenção do sistema condutor, hidrolisando o amido a açúcar, movendo este para a água presente no vaso e gerando pressão osmótica que leva a água a esta porção do vaso, evitando ou eliminando ar dos vasos largos (CARLQUIST, 1985).

Silva et al. (2011) relatam para M. ophthalmocentra a presença de parênquima axial escasso e acentuada quantidade de células com paredes espessadas e sugerem uma relação dessas características com deficiências minerais no solo. Mimosa catharinensis apresenta características similares e, avaliando as duas únicas localidades de ocorrência da espécie, observa-se que igualmente esse fator edáfico pode ser relacionado. As duas únicas áreas de ocorrência da espécie são igualmente caracterizadas por solos de baixa fertilidade; uma população ocupa terreno arenoso de restinga e a outra encosta de solo raso e pedregoso (MEDEIROS, 2014).

Mimosa catharinensis apresenta raios homogêneos, contudo células das extremidades são usualmente mais altas e curtas, embora procumbentes. Raios fracamente heterogêneos são registrados em diversas espécies do gênero incluindo M. scabrella (COZZO, 1951; MARCHIORI, 1980; 1995), M. daleoides (MARCHIORI, 1982), M. eriocarpa (CARNIELETTO; MARCHIORI, 1993), M. sparsa (MACCARI; MARCHIORI, 1994), M. pilulifera (MARCHIORI; BOLZON DE MUÑIZ, 1997b).
Oliveira et al. (2006) indicam para M. tenuiflora a presença de raios heterogêneos, com células procumbentes e quadradas, porém estudo posterior (SILVA et al., 2011) registra presença de raios homogêneos; Marchiori e Bolzon de Muñiz (1997a) registram para M. trachycarpa raios tipicamente homogêneos. Silva et al. (2011) mencionam que a variação dos raios em relação à composição (homogêneos ou heterogêneos) e quanto ao número de células de largura parece ser um caráter variável no gênero ou mesmo numa própria espécie.

A combinação de raios homogêneos de células procumbentes com ausência de estratificação é aventada como uma possível tendência evolutiva em Leguminosae (BARETTA-KUIPERS, 1981). Ainda que alguns autores sugiram um valor taxonômico do caráter (MARCHIORI; DE MUÑIZ, 1997a; 1997b), os dados mostram que sua consistência é baixa, já que as variações são encontradas em espécies das distintas seções e, como mencionado, até mesmo na descrição de uma dada espécie o registro desse caráter pode variar.

Mimosa catharinensis apresenta raios curtos, semelhantes a $M$. ophthalmocentra, $M$. tenuiflora, $M$. artemisiana, M. eriocarpa, M. incana, M. pilulifera, M. sparsa e M. bimucronata (CARNIELETTO; MARCHIORI, 1993; MARCHIORI, 1993; 1996; MACCARI; MARCHIORI, 1994; PAULA, 1995; MARCHIORI; BOLZON DE MUNIZ, 1997a; SILVA et al., 2011), podendo representar uma característica predominante no gênero, contudo diversos dos autores citados alertam para a necessidade de complementar essa análise com uma quantidade maior de espécies.

Mimosa catharinensis apresenta fibras libriformes não septadas, curtas a muito curtas, mostrando assim grande similaridade com as demais espécies de Mimosa estudadas. As características associadas às fibras apresentam uma grande homogeneidade no grupo, basicamente todas as espécies estudadas apresentam fibras libriformes não septadas, curtas a muito curtas, estreitas com paredes delgadas a espessas e pontuações simples. O tecido fibroso em Mimosa reforça a observação de Evans et al. (2006) que caracteriza o lenho do grupo como muito homogêneo e distinguível das outras duas subfamílias de Leguminosae. 
Com densidade de $0,59 \mathrm{~g} / \mathrm{cm}^{3}, M$. catharinensis tem sua madeira classificada como de densidade média. A proeminência das fibras na estrutura da madeira contribui para essa característica. Em geral madeiras de maior densidade apresentam uma maior resistência mecânica e alto valor energético, estando a densidade diretamente relacionada à quantidade de celulose $\mathrm{e}$ lignina que a constitui (ANGYALOSSY et al., 2005), bem como a espessura da parede das fibras (FUJIWARA et al., 1991).

Brandes e Barros (2008), estudando a anatomia do lenho de oito espécies de lianas da família Leguminosae, relatam que em todas as espécies as fibras representam uma pequena parte do xilema secundário. Registra-se aqui que as características das fibras em $M$. catharinensis não seguem esse padrão, assim sendo, o hábito lianescente não induziu sua variação. Leguminosae é conhecida como uma das famílias mais representativas em número de espécies de lianas nos trópicos (GENTRY, 1991), e estudos na Mata Atlântica (RESENDE; RANGA, 2005) reforçam essa observação. Mimosa catharinensis não é uma liana típica, caracterizando-se mais propriamente como um arbusto lianescente, e a adoção desse hábito mostra reflexos na estrutura dos vasos, porém não no tecido fibroso. Não obstante, a principal característica distintiva no lenho de $M$. catharinensis, qual seja o dimorfismo de vasos, mostra estreita correlação com o hábito lianescente.

\section{Referências}

ALVES, S. P. de; ANGYALOSSY-ALFONSO, V. Ecological trends in the wood anatomy of some Brazilian species. IAWA Journal, Leiden, v. 21, n. 1, p. 3-20, 2000.

ANGYALOSSY, V.; AMANO, E.; ALVES, E. S. Madeiras utilizadas na fabricação de arcos para instrumentos de corda: aspectos anatômicos. Acta Botanica Brasilica, Belo Horizonte, v. 19, n. 4, p. 819-834, 2005.

BAMBER, R. K.; TER WELLE, B. J. H. Adaptative trends in the wood anatomy of lianas. In: IQBAL, M. (Ed.). Growth patterns in vascular plants. Portland: Dioscoroides Press, 1994. p. 272-287.

BARETTA-KUIPERS, T. Wood anatomy of Leguminosae: its relevance to taxonomy. In: POLHILL, R. M.; RAVEN, P. H. (Ed.). Advances in legume systematics. Londres: Royal Botanic, 1981. p. 677-715.

BRANDES, A. F. N.; BARROS, C. F. Anatomia do lenho de oito espécies de lianas da família Leguminosae ocorrentes na Floresta
Atlântica. Acta Botanica Brasilica, Belo Horizonte, v. 22, n. 2, p. 465-480, 2008.

BUKATSCH, F. Bemerkungen zur Doppeffärbung AstrablauSafranin. Mikrokosmos, Stuttgart, v. 61, n. 8, p. 255, 1972.

BURKART, A. Leguminosas Mimosoideas. In: REITZ, R. (Ed.). Flora ilustrada catarinense. Parte I. Itajaí: Herbário Barbosa Rodrigues, 1979. p. 158-161.

BURKART, A. Las leguminosas argentinas silvestres y cultivadas. Buenos Aires: ACME, 1952. 569 p.

BURKART, A. Leguminosas. In: BURKART, A.; BURKART, N. S. T. de; BACIGALUPO, N. M. Flora ilustrada de Entre Rios (Argentina). Tomo Vol. 6. Buenos Aires: Coleccion Cientifica del INTA, 1987. p. 442-738.

CARLQUIST, S. Observations on functional wood histology of vines and lianas: vessel dimorphism, tracheids, vasicentric tracheids, narrow vessels, and parenchyma. Aliso, Claremont, v. 11, n. 2, p. 139-157, 1985.

CARLQUIST, S. Anatomy of vine and liana stems: a review and synthesis. In: PUTZ, F. E.; MOONEY, H. A. (Ed.). The biology of vines. Cambridge: Cambridge University Press, 1991. p. 53-72.

CARLQUIST, S. Comparative wood anatomy: systematic, ecological and evolutionary aspects of Dicotyledon wood. Berlim: Springer-Verlag, 2001. 448 p.

CARNIELETTO, C.; MARCHIORI, J. N. C. Anatomia da madeira de Mimosa eriocarpa Benth. Ciência Florestal, Santa Maria, v. 3, n. 1, p. 107-120, 1993.

COPANT - COMISSÃO PANAMERICANA DE NORMAS TÉCNICAS. Descrição macroscópica, microscópica e geral da madeira. Copant, São Paulo, v. 30, p. 1-19, 1974.

COZZO, D. Anatomia del leño secundario de las leguminosas mimosóideas y caesalpinoideas argentinas silvestris y cultivadas. Revista Instituto Nacional de Investigación de las Ciencias Naturales - Ciencias Botánicas, Buenos Aires, v. 2, n. 2, p. 63 290, 1951.

EVANS, J. A.; GASSON, P. E.; GWILYM, P. L. Wood anatomy of the Mimosoideae (Leguminosae). IAWA Journal Supplement, Leiden, v. 5, p. 1-118, 2006.

EWERS, F. W.; FISHER, J. B.; FICHTNER, K. Water flux and xylem structure in vines. In: PUTZ, F. E.; MOONEY, H. A. (Ed.). The biology of vines. Cambridge: Cambridge University Press, 1991. p. 127-160

FISHER, J. B.; EWERS, F. W. Wound healing in stems of lianas after twisting and girdling injuries. Botanical Gazette, Chicago, v. 150, n. 3, p. 251-265, 1989.

FREUND, H. Handbuch der mikroskopie in der technik. Frankfurt: Umsham Verlag, 1970. 375 p.

FUJIWARA, S.; SAMESHIMA, K.; KURODA, K.; TAKAMURA, $\mathrm{N}$. Anatomy and properties of japanese hardwoods I. Variation of fibre dimensions and tissue proportions and their relation to basic density. IAWA Bulletin, Leiden, v. 12, p. 419-424, 1991.

GENTRY, A. H. The distribution and evolution of climbing plants. In: PUTZ, F. E.; MOONEY, H. A. (Ed.). The biology of vines. Cambridge: Cambridge University Press, 1991. p. 3-50.

IUCN. IUCN red list of threatened species. Version 2013.2. 2013. Disponível em: <www.iucnredlist.org>. Acesso em: 12 maio 2014. 
IAWA COMMITTEE. IAWA list of microscopic features for hardwood identification. IAWA Bulletin, Leiden, v. 10, n. 3, p. 219-332, 1989.

MACCARI, A.; MARCHIORI, J. N. C. Estudo anatômico do xilema secundário de Mimosa sparsa Benth. Ciência Florestal, Santa Maria, v. 4, n. 1, p. 145-155, 1994.

MARCHIORI, J. N. C. Estudo anatômico do xilema secundário e da casca de algumas espécies dos gêneros Acacia e Mimosa, nativas no estado do Rio Grande do Sul. 1980. 186 f. Dissertação (Mestrado em Engenharia Florestal) - Universidade Federal do Paraná, Curitiba. 1980.

MARCHIORI, J. N. C. A estrutura do xilema secundário de Mimosa daleoides Benth. (Leguminosae Mimosoideae). Ciência e Natura, Santa Maria, v. 4, p. 107-113, 1982.

MARCHIORI, J. N. C. Anatomia da madeira de Mimosa cruenta Benth. (Leguminosae Mimosoideae). Ciência e Natura, Santa Maria, v. 7, p. 73-81, 1985.

MARCHIORI, J. N. C. Anatomia da madeira e casca do maricá, Mimosa bimucronata (DC.) O. Kuntze. Ciência Florestal, Santa Maria, v. 3, n. 1, p. 85-106, 1993.

MARCHIORI, J. N. C. Anatomia da madeira e casca da bracatinga, Mimosa scabrella Benth. Ciência e Natura, Santa Maria, v. 1, p. 115-132, 1995.

MARCHIORI, J. N. C. Anatomia do xilema secundário de Mimosa incana (Spreng.) Benth. Ciência Florestal, Santa Maria, v. 6, n. 1, p. 53-63, 1996.

MARCHIORI, J. N. C.; BOLZON DE MUÑIZ, G. I. Anatomia do xilema secundário de Mimosa pilulifera Benth. Ciência Florestal, Santa Maria, v. 6, n. 1, p. 65-75, 1997a.

MARCHIORI, J. N. C.; BOLZON DE MUÑIZ, G. I. Anatomia do xilema secundário de Mimosa trachycarpa Benth. Ciência Rural, Santa Maria, v. 27, n. 2, p. 223-228, 1997 b.

MEDEIROS, J. D. Fruit description and preliminary analysis on reproductive phenological data of Mimosa catharinensis Burkart (Leguminosae-Mimosoideae). Pensee Journal, Paris, v. 76, n. 5, p. 113-122, 2014.
MMA. Instrução normativa no 06, de 23 de setembro de 2008. 2008. Disponível em: <http:/www.mma.gov.br/estruturas/179/ arquivos/179 05122008033615.pdf>. Acesso em: 12 maio 2014.

MUNSELL COLOR. Munsell soil color charts. Maryland: Kollmorgen corporation, $1975.13 \mathrm{p}$.

PAULA, J. E. de. Anatomia e dendrometria de Mimosa artemisiana e Eucalyptus grandis. Pesquisa Agropecuária Brasileira, Brasília, v. 30, n. 6, p. 745-757, 1995.

PUTZ, F. E.; HOLBROOK, N. M. Biomechanical studies of vines. In: PUTZ, F. E.; MOONEY, H. A. (Ed.). The biology of vines. Cambridge: Cambridge University Press, 1991. p. 73-98.

RAMBO, B. Leguminosae Riograndense. Instituto Anchietano de Pesquisas, São Leopoldo, v. 23, p. 1-166, 1966.

RESENDE, A. A.; RANGA, N. T. Lianas da Estação Ecológica do Nordeste Paulista, São José do Rio Preto/Mirassol, SP, Brasil. Acta Botanica Brasilica, Belo Horizonte, v. 19, p. 273-279, 2005.

RICHTER, H. G.; CHARVET, L. M. Estudo e pesquisa sobre Mimosa scabrella. Floresta, Curitiba, v. 4, n. 2, p. 68-69, 1973.

OLIVEIRA, E.; VITAL, B. R.; PIMENTA, A. S.; DELLA LUCIA, R. M.; LADEIRA, A. M. M.; CARNEIRO, A. C. O. Estrutura anatômica da madeira e qualidade do carvão de Mimosa tenuiflora (Willd.) Poir. Revista Árvore, Viçosa, v. 30, n. 2, p. 311-318, 2006.

SILVA, L. B.; SANTOS, F. A. R.; GASSON, P.; CUTLER, D. Estudo comparativo da madeira de Mimosa ophthalmocentra Mart. ex Benth e Mimosa tenuiflora (Willd.) Poir. (FabaceaeMimosoideae) na caatinga nordestina. Acta Botanica Brasilica, Belo Horizonte, v. 25, n. 2, p. 301-314, 2011.

WHEELER, E.; BAAS, P. Fossil wood of the Leguminosae: a case study in xylem evolution and ecological anatomy. In: HERENDEEN, P. S.; DILCHER, D. L. (Ed.). Advances in Legume Systematics 4. Londres: Royal Botanic Gardens, 1992. p. 281-301. 